\title{
A Cognitive Study of Preposition Ellipsis in Radiotelephony Communication
}

\author{
Wei Chen \\ Southwest University, Chongqing, China \\ Email: 1052080575@qq.com
}

How to cite this paper: Chen, W. (2016). A Cognitive Study of Preposition Ellipsis in Radiotelephony Communication. Open Journal of Modern Linguistics, 6, 390-400.

http://dx.doi.org/10.4236/ojml.2016.65035

Received: September 14, 2016

Accepted: October 15, 2016

Published: October 18, 2016

Copyright $\odot 2016$ by author and Scientific Research Publishing Inc. This work is licensed under the Creative Commons Attribution International License (CC BY 4.0).

http://creativecommons.org/licenses/by/4.0/

\begin{abstract}
The research on the omission in the field of linguistics can be divided into the perspective of transformational generative grammar and functional grammar. The research on the omission from the perspective of transformational generative grammar is mainly embodied in the present study of the empty category, and the function of omission is regarded as an important means to make textual coherence. This paper attempts to apply the findings in cognitive linguistics to study ellipsis in radiotelephony communication in English, with the theory of cognitive linguistics to explain in detail the ellipsis of radiotelephony communication and ellipsis, to the maximum extent to avoid ambiguity or misunderstanding appear radiotelephony communication among different users.
\end{abstract}

\section{Keywords}

Ellipsis, Radiotelephony Communication, Cognitive Linguistics

\section{Introduction}

Radiotelephony communication usually refer to the dialogue between controller and pilot language communication. The research object is not limited to language standard in radiotelephony communication, but in a real dialogue is as the object of analysis. The international civil aviation organization made detailed provisions on the more than and 30 term contains ellipsis sentences or holophrastic instruction radiotelephony communication. Because each pilot radio time is limited, there are a lot of ellipsis phenomenon of radiotelephony communication. The domestic related research radiotelephony communication start up late and flight English is extremely lack of systematic study on the analysis of ellipsis in radiotelephony communication. The foreign study on radiotelephony communication is mainly reflected on the relevant provisions of the detailed interpretation and teaching (Croft, 2004). Domestic flight institute 
experts on the main achievements of Radiotelephony Communication English are about flight accident case analysis or safety research. Professor Xiao Ling pointed out that in the case of accidents in the global aviation accidents are about seventy percent language related. In Chinese, preposition is always a completive with strong adhesiveness, which could introduce nominal element and be sticked into a preposition phrase with noun or noun phrase so as to express the semantic relation between this noun and the verb and as a result complete a certain grammatic meaning to the sentence. However, some prepositions can be omitted in certain context without influencing the communications between listener and the speaker on the premise that the semantics are clear and out of the pragmatic demands. This is also one aspect that indicates the flexibility and simplicity of the Chinese grammar. There are various divisions on the types of omission. Divisions on their types are becoming increasingly concrete. Quirk pointed out that language omission is mainly used to avoid repetition. Different passages have their own features on the analysis of the types of omission. Some of them are essentially the same although they look different. Generally speaking, the omission types scholars generally agree are as follows: 1) zero anaphoric constituent; 2) previous omission; 3) diaglogue omission (Langacker, 1993).

Scholars in TG grammar and cognitive linguistics field have been doing a lot of research in the field of linguistics. Chinese grammar analysis, the traditional grammar basically is the omission of syntax, syntactic structure and filling comprehension of omission. Ellipsis is a language phenomenon in communication which usually occurs in such a silent way that more often than not we overlook it without realizing its existence (Halliday, 1994).

After we have introduced the development of cognitive linguistics, we have found that cognitive linguists have put forward various theoretical exploration of default semantics. Omitted elements in default semantics have been described as the omission of some words. Although typical examples of default semantics have been analyzed by the processes of prominence theory, the purpose of this paper is to analyze ellipsis circumstances in radiotelephony communication. Existing researches mainly discussed the proposition model in fixed written form and idealized cognitive model (Croft, 2004).

The domestic and foreign research about the omission of radiotelephony communication is not much, but the research on ellipsis has a French linguist Martine (Martinet) pointed out that people in verbal communication often use economic language or fewer words to convey more information. Although only from the syntactic structure, it is not complete, but its semantic meaning is clear and complete in the certain context of communication. Ellipsis phenomena frequently appear in the phone, which reflects one of the basic principles of the radiotelephony communication (Economy Principle).

A cognitive study of radiotelephony communication ellipsis in the innovation of the paper lies in the theories of cognitive linguistics research is applied to Civil Aviation English. This paper is from the perspective of cognitive pragmatics study of preposition ellipsis phenomenon in conversation (Croft, 2004). 


\section{The Characteristics and Causes of the Phenomenon of Preposition Omission}

It is assumed in cognitive linguistics that grammar is not autonomous, which is entirely due to the syntactic structure of the semantic and pragmatic factors in a sense is widely accepted. As a whole, we believe that the field of linguistics to omit many syntactic, semantic and pragmatic aspects, it is absolute, changes in many other aspects, changing the structure of the usual result. First of all, this is the essence of the theory that we give a brief introduction to the omission of the theoretical basis: the default semantics and prominance theory, which can help us to establish the theoretical framework It is widely accepted in Cognitive Linguistics that syntax is not autonomous that the syntactic construction was totally influenceed by semantic and pragmatic factors in some sense. And viewed as a whole, we believe that ellipsis relates many linguistic domains such as syntax, semantics, pragmatics, etc. It is absolute that a structural change usually results in changes in many other sides (Croft, 2004).

\subsection{Research Results on Omission}

In 1980s, due to the development of syntactic, semantic and pragmatic linguistics, studies on ellipsis linguists put forward the concept of semantic ellipsis and pragmatic ellipsis. Along with the continuous development of transformational generative grammar, functional linguistics, text linguistics and cognitive linguistics, Wang Weixian, Lv Shuxiang and so on have done the research on the phenomenon of Chinese omission.

The principle of functional grammar is regarded as an important means to make textual coherence. In the description of systemic functional grammar, there is a vacancy in the speech or syntactic structure in the discourse, which can be filled in the context of the context. In the system of functional grammar description, the omission of the classification can be divided into grammatical ellipsis, semantic ellipsis and pragmatic ellipsis, but these three categories cannot avoid coincidence and coexistence (Allerton, 1975). Therefore, this paper not only distinguish between grammatical ellipsis and and pragmatic ellipsis but also devide them into ellipsis of nouns, verbs and prepositions no, the omission of radiotelephony communication. This paper attempts to apply the findings in cognitive linguistics to study professional flight radiotelephony communication in English by using the theory of cognitive linguistics to explain in detail the ellipsis of radiotelephony communication and ellipsis. The analysis aim to avoid ambiguity or misunderstanding appear radiotelephony communication among different users.

\subsection{Causes of Omission}

With the development of cognitive linguistics, there are more and more high degree of specialization, cognitive linguistics related papers and books. After 2000 with the great development of civil aviation, fruitful theoretical results of linguistics is used to solve the practical problems in radiotelephony communication or some other kind of specific subjects. The air ground calls in radiotelephony communication are accompanied with higher frequency of subject omission, such as omission of I. According to the division 
such as noun ellipsis, verb ellipsis and the preposition ellipsis, there are various types of air conversation ellipses. In this paper, we use the zero form to stand for the omission of preposition. There is a close relationship between the omitted preposition and context. common knowledge background of the speaker and the hearer sharing can also constitute omission. The the omission will also appear if the topic of information is already known to the hearer (Goldberg, 1995).

In radiotelephony communication preposition ellipsis are generated by subjective and objective reasons. On the one hand the speaker tends to give economic instruction, on the other hand, the radio talk time is extremely limited which requires the speaker to briefly express. There is the ellipsis of radiotelephony communication in a limited radio time generated by this context if the flight controller and pilot shared the similar cognitive context.

In the Civil Aviation English, economic principle is often the principle of the controller. However, the principle of economic principles and the flight crew's need of understanding of have to achieve a balance (Lakoff, 1993). From the view of air traffic controller, using the language of ellipsis is more economical, but from the pilot's point of view, cognition and comprehension are omitted from the discourse which needs more effort.

The omission of prepositions in radiotelephony communication is conditional. Ellipsis must satisfy the conditions that must be able to disambiguate the cognitive context or context. The economic nature of the omission of words can not cause the ambiguity of language. If the ambiguity or misunderstanding of the telephone is easy to occur, it can not be omitted. In relation to the special flight instructions, they must use the complete form. The controller and pilot need to reduce the cognitive effort needed in the process of understanding. The omission of radiotelephony communication is the default phenomenon of the syntactic level in the actual use of language, but the ellipsis and semantics and pragmatics are closely related.

We study the preposition in ellipsis radiotelephony communication from the perspective of default semantics. The main pragmatic ellipsis often appear in the specific context and the pragmatic study of preposition ellipsis cannot be explored without the speaker and the hearer's common knowledge.

\section{The Cognitive Process of Omission}

Elliptical sentences are concise and short where the known message for the listener and the speaker is omitted in certain context in case of the misunderstanding of the listener and the speaker. Furthermore, it enables the listener to better understand the opposite's goal for expression (Cruse, 1986). As elliptical sentence can avoid from repeating the message commonly known by the speaker and the listener and makes the expression more concise, compact and clear. As we know, the development of any language has a common trend, namely "economic trend", numerous elliptical sentences in the communicative process is a reflect of economic principle in the modern Chinese. The most pragmatic function of elliptical sentence is economic and labor saving. 
Besides, elliptical sentence has its unique cognitive process.

Over a long time, elliptical sentences have always been the focus on the study of Chinese grammers in both home and abroad. In the past, Chinese grammarians' study on omission mainly centered on the descriptions on elliptical elements and types. Although mere on the static descriptions, these descriptions draw out a general outline for the omission of syntactic elements in modern Chiense and are of significant reference value to our later study.

On the basis of the fruits of our predecessors, this thesis attempts to use the three-level theory to analyze and explore the elliptical sentences, especially on the pragmatic level. Given the limit of predecessor's study on elliptical elements, this thesis attempts to analyze preposition omission; based on the truth that omission is a pragmatic phenomenon, it analyzes the elliptical sentences' distribution in various styles and explores the reasons; explore the relations between elliptical sentences and styles combining the concrete situation; meanwhile, analyze the pragmatic function of elliptical sentence (Thornburg \& Panther, 1997). The analysis of this thesis indicates that besides omission of major syntactic elements, study on the omission of prepostion is also possible and should be focused on; study of omission should be put in a dynamic context and be analyzed combining different styles.

The omission of prepositions in the conversation is not only related to the structure of the verb phrase, but also highly related to the semantic condition of the context of the verb phrase. Different languages for phrasal verb preposition ellipsis are not the same. The same semantic Chinese preposition ellipsis is rare in radiotelephony communication.

The cognitive interpretation of semantic omission often requires reference to context in the pragmatic level. We believe that the theory of pragmatic inference, which is based on the context structure, provides another perspective for the cognitive interpretation of the omission. The context of "state of affairs" theory is essentially a conceptual metonymy. Panther and Thornberg put forward the "scenario". They pointed out that the context refers to a series of events, including events before the scenario part (BEFORE), such as motivation potential scenario can cause the occurrence of events. It is the core part of the existing scenario. This effect is keeping up with the scenario of the necessary consequences. The situation after part (AFTER), is a scenario of non essential consequences (Warren, 1999). For example:

Tower: Cansle Xinjin. Divert to Suining airport. CCA102

Pilot: Divert Suining, CCA102.

The idealized cognitive model of Suining includes a lot of CM:

1. Suining government;

2. Suining people;

3. Suining airport, etc.

In this example, Suining airport this model to supplement the omitted form of Suining.

Both ellipsis on the period of radiotelephony communication, there are semantic ellipsis. Among them, "Suining Divert" is the highlight of the new information, and "the 
tower and Xinjin airport" are not the highlight of the information. At the same time, it is also a travel radiotelephony communication environment, including the premise (contact tower), ride (a change of course for Suining), (Suining Road), nuclear (approach), end point (destination) and other five events. The premise part, namely contact tower event as a reference point for cognitive highlight to activate the entire travel scene. In the whole journey, other events including the preposition to are omitted, and the omission of many prepositions are not alone which are accompanied by other syntactic components omitted.

\subsection{Preposition Ellipsis in Radiotelephony Communication}

If the air before the conversation has appeared in the complete form of prepositions, after the dialogue omitted in this paper will be described as preposition ellipsis phenomenon prepositions. The following appeared in the times of radiotelephony communication preposition ellipsis:

P: Beijing Control, CCA102, request taxi.

$\mathrm{C}$ : CCA102, taxi via taxiway $\mathrm{M}$ and $\mathrm{C}$ to holding point runway $36 \mathrm{R}$, wind 240 degrees, $8 \mathrm{~m} / \mathrm{s}$, QNH 1012.

$\mathrm{P}$ : taxi via taxiway $\mathrm{M}$ and $\mathrm{C}$ to holding point runway $36 \mathrm{R}$, wind 240 degrees, $8 \mathrm{~m} / \mathrm{s}$, QNH 1012. (read back the instruction)

C: read back correct.

P: Beijing Tower, CCA102, approaching holding point runway 36R.

C: CCA102, line up and ready for immediate departure.

P: lining up , CCA102.

C: CCA102,clear to destination, flight planned route, follow D05, initial climb to 900m and maintain, squawk 4325.

P: clear to destination, flight planned route, follow D05, initial climb $900 \mathrm{~m}$ and maintain, squawk 4325, CCA102.

The call "climb to" and "descend to" with digital flight height, the preposition "to" is often omitted, as in "initial climb to $900 \mathrm{~m}$ with and maintain" controllers say it is using "climb to" and the pilot repeat omit the "to". The frequency of he preposition ellipsis appears in radiotelephony communication is high. "Approaching holding point runway 36R" approaching to "can be restored to holding point at runway 36R" in the regular English. In daily English "approach to" is a relatively fixed collocation form, but in the flight of radiotelephony communication, "to" ellipsis is acceptable. "To initial climb 900m ellipsis and maintain" is a typical civil aviation English where "to" is omitted, In the "climb to" followed by the height of the digital, in order to avoid confusion and the number "two" often appear but the preposition "to" is omitted. while in the above call scenario, "approaching holding point (at) runway 36R" "at" is the omission which does not affect the flight and control information exchange. A typical example is the "at the airport arrival" is often omitted as "the airport arrival".

According to the memory-focus theory, the understanding of the sentence containing the omission depends on the cost and benefit. Refering the current topic, prepositions 
and action verbs integration is immediate and many verbs and prepositions in a fixed phrase exists in the form of the speaker and the hearer's cognition. Language dominant verbs tend to be in focus, while a call statement after a preposition followed by verbs, prepositions and verbs are more closely associated with the verb, prepositional phrases in general focus, so the preposition understanding effort less, low cost and high profit. Plenty use of elliptical sentences with preposition omission in some speech works always makes the speech more live and precise. As a result, reader can experience a different rhythm in reading and feel a different living rhythm. Idiom or four-character structures are fixed or semi-fixed phrases with rich meaning, when they are completed with prepositions, no idiom or four-character structures should be called (Sperber \& Wilson, 1995).

In other words, the omission of prepositions is generally in the focus, so the understanding of the zero form is less, but the cost is very low, which fully reflects the economy principle of language.

\subsection{Misunderstanding of Preposition Ellipsis in Radiotelephony Communication}

In conventional English, due to less influence on the semantic meanings, preposition ellipsis is less studied. However, in Civil Aviation English due to the preposition "to" and the number "two" must strictly distinguish, the preposition "to" can be omitted so as to avoid the flight accident. In February 1990, the British Flying Tiger Airlines Boeing 747 cargo plane at KualaLumpur Airport, the tower controller instructions are: descend two four zero zero (down to 2400 meters), the tower to omit the preposition "to" in the call statement. The pilot's understanding is: descend to four zero zero (down to 400 meters), which causes the aircraft down to 473 meters and hit the ridge. Obviously, the similarity of "two" and "to" is a direct cause of the accident, and the preposition ellipsis has become one of the Civil Aviation English debate.

In the context of radiotelephony communication, "descend" provides psychological accessibility for "descend to". The word "descend" was set as the cognitive reference point to arouse the less prominent project "to". "Descend to" as a whole concept is airline pilot's understanding. The words "descend" and "to" form image and background. The word "to" as the background is omitted, not yet manifested in speech.

\subsection{Context}

Omission and omission elements on syntactic, semantic and pragmatic levels are different from each other. It points out the omission of subject, object and modifier. The omission of subject, object and verb. Wang Li makes the first overall discussion on omission elements in the Modern Chinese Grammers. We make a detailed description on the syntactic elements which could be omitted.

As an independent sentence, elliptical sentence must be described and studied combining with the concrete context where it exists. The relation between elliptical sentence and context is like the relation between fish and water. Its value cannot be 
fully expressed except in context. Once leaving the context, the elliptical sentence will not be alive. Only in concrete context, proper and accurate analysis can be made. Speaking of context and omission, let's talk about our recognition on context. Context is a basic concept in pragmatics. The content of context is comparatively complexed. Based on analysis of pragmatic study of preposition ellipsis in radiotelephony communication. In the context of ellipsis in radiotelephony communication, recovery and understanding plays an important role in the analysis (Taylor, 1995). Based on existing context, speaker generated an omission in the practical use. Then the hearer can fill in a comprehensive understanding of the meaning in a certain context. Filling and recovery play crucial role for the correct understanding of radiotelephony communication.

Situational context refers to the context being composed of context factors such as time, place, occasion, situation, topic and event which are directly connected with the communication field. It's not necessary for ticket inspector to speak "please hand over your ticket" in full. Similarly, due to the completion of time message, the elements can always be omitted in speech. Being restricted by the existing context, it's not necessary to utter the complete sentence in the principle of saving labor out of linguistic communication. As the major elements in the known message from the situational context are the daily accumulated experiences and knowledge in our memory, namely the knowledge background or memory bank that we used to talk about. Association on the other matter will naturally form in our mind when we meet some specific events based on common sense. This is the foundation on which people communicate with and understand various information. Besides language-as-the information, the linguistic information on events which people are familiar whith have long entered the memory bank of people's mind. In communication, people will naturally omit the words that transport common sense message and the message receiver will be able to complete the common sense for better understanding while not cause misunderstanding and ambiguity (Levinson, 1995).

In situational context, if taking the psychological image of the on-site live as sentence element, as the words and sentences being used in communication depends on situational context, some self-evident elements in a certain situational context can be omitted and will not influence the normal communicative activity between the speaker and the listener as the communicative activity can get the meaning of words by completeing message based on the on-site live dialogue.

Therefore, with the help of context, completency of speech is not necessary. In elliptical sentence, the unknown message is in the evident position while commonly known message that disturbs both parties is omitted. In some occasions, numerous elliptical sentences won't influence the communication, instead, are helpful to the success of the communicative goal. Conversely, if elliptical sentences are not used, we can also capture the main information in the principle of end weight, however time will be wasted which evidently doesn't fit the economic principle. The above truth indicates that during the transfer of message, elliptical sentence can be used to outstand the focus of message and fit both parties' demand on high efficiency and economy (Taylor, 1995). 
People in the process of communication can choose different expression methods based on the demand of communication, namely language is as important as the aided communicative tool, communicative context and verbal language which can expresses a certain meaning. In concrete expression, people will determine which one to choose or which one to use more when express in a concrete manner (Lakoff \& Johnson, 1999). Generally speaking, people usually comprehensively determine the final expression method in the principle of saving labor along with the pragmatic effect. Whereas, the pragmatic effect principle is still involved with the listener's acceptance over the communicative context and as to the speaker, it is a matter of communicative context reality (Saeed, 1997). Only when the speaker thinks that the communicative context may be accepted by the listener could the speaker adopts elliptical sentence, otherwise,you could only give up the communicative context. Communicative context refers to the context of factors which are connected with the personal features of the communicator. For instance, the context being composed of posture, privity, style, relation, emotion and target, etc..

In order to precisely express, we can also omit some contents according to the context so as to avoid from being repetitive, and outstand new message and make the context being more closely adhesioned. If there is no context, you should not omit like this in case of ambiguity. As omission is a pragmatic phenomenon, we consider that we should discuss about the elliptical sentences in radiotelephony communication from the aspect of context. Privity context makes the talk more easily to be master. Therefore, although the speaker uses elliptical sentence in communications, the listener could also compensate these changing sentence structure so as to properly master the discourse structure and accurately understand the content of discourse.

We hold that the context refers to the environment that formed by own factors of the language in the application of the language, it is composed of many forms like sentences, sentence group, paragraphs or chapters. Proper and accurate understanding of the omission of syntactic elements should be based on the context which could produce dynamic meaning for the speeck. When Lv Shuxiang talked about the omission, she clearly points out the close relation between structural omission and context. This opinion has been widely accepted in the grammar circle. Many theses are self-consciously hooked with context. Therefore, the existence of elliptical sentence cannot leave the context, and you have to fully utilize the context so as to master the omission of syntactic elements (Pustejovsky, 1995). Due to the rapid development of computer linguistics, research in the communication of ellipsis and ellipsis recovery for future large aircraft self driving computer man-machine dialogue, voice control car system computer has important significance for natural language understanding, but also has a positive effect on the flight and control the terminology standard. Radiotelephony communication is essentially a standard English based dialogue is very flexible, in the actual application, especially in the controller are native speakers of English under the condition of radiotelephony communication showed a flexible attribute of natural language, natural language provides people with a rich means of expression of thought, 
but it is a rich and flexible the computer features lead to the tremendous difficulties in language processing, linguists and computer scientists began more and more research attention omitted, we hope that through analysis of ellipsis in radiotelephony communication for radiotelephony communication teaching provides theory foundation of theory and Chinese civil aviation aircraft support man-machine dialogue (Searle, 1979).

\section{Conclusions}

Omission of prepositions in radiotelephony communication involves grammar, syntax, and semantics, phonetics, rhetoric, psychology and sociology. The omission of prepositions in radiotelephony communication is a complex linguistic phenomenon. The study of radiotelephony communication radio conversation will be helpful to fix relevant documents and materials in written form. The study of preposition omission has an important role to flight safety in a long time.

This paper integrates the research results of cognitive linguistics on the omission into practical application of aviation English. The Aviation English study gradually began to pay attention to the omission, but the domestic research of Aviation English is lack of professionals and systemetic study.

Being limited by the author's ability and omission itself is a tendancy instead of a conventionality, therefore, the interpretations on elliptical sentences in this paper are somewhat inaccurate along with improper corpus. Other aspects not being involved to be further discussed. Being limited by the time and vigor of the author, the study on elliptical sentences in this theis are not complete, for instance, the semantic selection and restriction of elliptical sentence are not fully studied which requires more efforts in the future.

In summary, ellipsis is a common phenomenon in the process of language use. It exists in discourse, which is a prominent feature of daily conversation. Ellipsis in radiotelephony communication have subjective and objective reasons. Subjective reasons are entailed from the pilots and controllers' economic thoughts, while objective reasons are entailed from contextual factors in a variety of flight information and a lot of simplified abbreviations.

\section{References}

Allerton, D. J. (1975). Deletion and Proform Reduction. Journal of Linguistics, 1, 213-237. http://dx.doi.org/10.1017/S0022226700004540

Croft, W., \& Cruse, D. A. (2004). Cognitive Linguistics. Cambridge: Cambridge University Press. http://dx.doi.org/10.1017/CBO9780511803864

Cruse, D. A. (1986). Lexical Semantics. Cambridge: Cambridge University Press.

Goldberg, A. E. (1995). A Construction Grammar Approach to Argument Structure (pp. 7-159). Chicago: The University of Chicago Press.

Halliday, M. A. K. (1994). An Introduction to Functional Grammar. London: Edward Arnold. Lakoff, G. (1993). The Contemporary Theory of Metaphor. In: An. Ortony (Ed.), Metaphor and 
Thought (pp. 202-251). Cambridge: CUP. http://dx.doi.org/10.1017/cbo9781139173865.013

Lakoff, G., \& Johnson, M. (1999). Philosophy in the Flesh. The Embodied Mind and Its Challenge to Western Thought. New York: Basic Books.

Langacker, R. W. (1993). Reference-Point Constructions. Cognitive Linguistics, 4, 1-38. http://dx.doi.org/10.1515/cogl.1993.4.1.1

Pustejovsky, J. (1995). The Generative Lexicon. Cambridge: The MIT Press.

Saeed, J. I. (1997). Semantics. London: Blackwell Publishers Ltd.

Searle, J. (1979). Metaphor. In: A. Ortony (Ed.) Metaphor and Thought (pp. 92-123). New York: Cambridge University Press. http://dx.doi.org/10.1017/cbo9780511609213.006

Sperber, D., \& Wilson, D. (1995). Relevance: Communication and Cognition. Cambridge, MA: Harvard University Press.

Taylor, J. R. (1995). Linguistic Categorization: Prototypes in Linguistic Theory. Oxford: Clarendon.

Thornburg, L., \& Panther, K.-U. (1997). Speech Act Metonymies. In: N.-A. Liebert, G. Redeker, \& L. Waugh (Eds.), Discourse and Perspective in Cognitive Linguistics (pp. 205-219). Philadelphia: John Benjamins Publishing Company. http://dx.doi.org/10.1075/cilt.151.14tho

Warren, B. (1999). Aspects of Referential Metonymy. In: K.-U. Panther, \& G. Radden (Eds.), Metonymy in Language and Thought (pp. 121-135). Philadelphia: John Benjamins. http://dx.doi.org/10.1075/hcp.4.07war

Submit or recommend next manuscript to SCIRP and we will provide best service for you:

Accepting pre-submission inquiries through Email, Facebook, LinkedIn, Twitter, etc. A wide selection of journals (inclusive of 9 subjects, more than 200 journals)

Providing 24-hour high-quality service

User-friendly online submission system

Fair and swift peer-review system

Efficient typesetting and proofreading procedure

Display of the result of downloads and visits, as well as the number of cited articles Maximum dissemination of your research work

Submit your manuscript at: http://papersubmission.scirp.org/

Or contact ojml@scirp.org 